\title{
Surgical treatment of tubal ectopic pregnancy through posterior colpotomy: experience from a Brazilian university hospital
}

\author{
Tábata Longo da Silva Machado', Alysson Zanatta', Larissa Gonçalves Braz Santos', \\ Rafaella Ferreira de Araújo Litvin', Lizandra Moura Paravidine Sasaki', Júlio Elito Júnior², \\ Edward Araujo Júnior ${ }^{2,3}$, Alberto Moreno Zaconeta ${ }^{1}$
}

1Department of Obstetrics and Gynecology, University of Brasília (UnB), Brasília-DF, 2Department of Obstetrics, Paulista School of Medicine, Federal
University of Sao Paulo (EPM-UNIFESP), ${ }^{3}$ Medical Course, Bela Vista Campus, Municipal University of São Caetano do Sul (USCS), São Paulo-SP, Brazil

The objective of this study was to evaluate the feasibility of posterior colpotomy for the surgical treatment of tubal ectopic pregnancy in hemodynamically stable women. We performed a retrospective analysis of medical records obtained over a period of 18 months. Twelve cases were identified, with the following characteristics: mean gestational age, 7.7 weeks; mean serum $\beta$-human chorionic gonadotropin level, 7,786 mlU/mL; and greater diameter of the mass, 15-69 mm. Treatment was successful in all cases. Salpingectomy was performed in 10 patients (83.3\%) and salpingostomy, in 1 patient. The remaining patient only received peritoneal lavage, as the evidence of ectopic abortion with only a slightly dilated uterine tube was found during surgery. The mean surgical time was 42.5 minutes. In the analyzed cases, posterior colpotomy was found to be a feasible alternative method for the surgical treatment of tubal ectopic pregnancy in hemodynamically stable women.

Keywords: Tubal pregnancy; Operative surgical procedures; Colpotomy

\section{Introduction}

A pregnancy is termed ectopic when the blastocyst implants outside the uterine cavity, usually in the uterine tubes. Early diagnosis and treatment of this condition is of utter importance, as a ruptured tubal pregnancy is a considerable cause of hemorrhage-related maternal death [1].

The advent of transvaginal ultrasound along with the possibility of dosing serum $\beta$-human chorionic gonadotropin (hCG) have made it possible to diagnose early ectopic pregnancies, some of which can be managed with non-surgical approaches, such as expectant management and pharmacological treatment with methotrexate [2]. However, surgery continues to be the most important intervention for the prevention of tubal rupture and severe hemorrhage. Surgical treatment can be accomplished through laparotomy, laparoscopy, or incision of the posterior vaginal cul-de-sac, i.e., posterior colpotomy.

When equipment and qualified professionals are available, laparoscopy is preferred over laparotomy, as it has shown indisputable advantages in regards to tissue trauma, blood loss, surgical time, and post-operative recovery. In these conditions, laparotomy is reserved for severe cases with hemodynamic instability [3]. Conversely, when laparoscopy is unavailable and the patient is stable, approach through posterior colpotomy would be the most reasonable alternative, considering that it is a simpler procedure, with shorter surgical and hospitalization times, reduced blood loss, and faster

Received: 2018.12.19. Revised: 2019.04.07. Accepted: 2019.05.29. Corresponding author: Edward Araujo Júnior

Department of Obstetrics, Paulista School of Medicine, Federal University of São Paulo (EPM-UNIFESP), Rua Belchior de Azevedo, 156 apto. 111 Torre Vitoria, São Paulo-SP, Brazil E-mail: araujojred@terra.com.br https://orcid.org/0000-0002-6145-2532

Articles published in Obstet Gynecol Sci are open-access, distributed under the terms of the Creative Commons Attribution Non-Commercial License (http://creativecommons. org/licenses/by-nc/3.0/) which permits unrestricted non-commercial use, distribution, and reproduction in any medium, provided the original work is properly cited.

Copyright $\odot 2019$ Korean Society of Obstetrics and Gynecology 


\section{Obstetrics \& Gynecology Science}

Vol. 62, No. 6, 2019

return to daily activities, than laparotomy.

Despite the safety and the many advantages of accessing the pelvis through the vaginal route, posterior colpotomy is rarely cited in contemporary medical literature for the treatment of tubal ectopic pregnancy [4].

Herein, we present the experience of a university hospital in the surgical treatment of tubal ectopic pregnancy through posterior colpotomy.

\section{Case report}

Data collection: data of women who underwent surgery for ectopic pregnancy at the University Hospital of Brasilia (Brazil) from December 1, 2014 to May 30, 2016 were gathered retrospectively. Only cases treated through posterior colpotomy were analyzed.

Inclusion criteria: as laparoscopic equipment is currently used in elective procedures but is not routinely available in the emergency department at our hospital, surgical approach through posterior colpotomy was offered as an alternative to laparotomy to women with a diagnosis of ectopic pregnancy, hemodynamic stability, and one or more of the following criteria for poor prognosis in response to pharmacological treatment with methotrexate: 1) mass diameter on ultrasound of $\geq 35 \mathrm{~mm}, 2$ ) serum $\beta$-hCG level of $\geq 5,000 \mathrm{mIU} / \mathrm{mL}$, and 3) fetal cardiac activity. All women who underwent surgical treatment of ectopic pregnancy through posterior colpotomy during the abovementioned period were included.

Exclusion criteria: women with an immobile uterus on pelvic examination were not offered posterior colpotomy as an alternative treatment, as this finding suggests severe pelvic adhesions that could lead to complications.

Surgical technique: 1) placement of patients in the lithotomy position, with the thighs flexed at $45^{\circ}$ to $60^{\circ}$ upward at the hips, 2) placement of a weighted speculum, propped against the posterior vaginal wall, 3) displacement of the anterior vesical wall and exposure of the uterine cervix using a Breiski valve, 4) clamping and traction of the posterior border of the cervix, 5) creation of an incision in the transition between the mucosa of the posterior vaginal wall and the uterine cervix, using a 40-W electrocautery device or scissors, followed by dissection of the vaginal wall, 6) drainage of free blood in the cavity, 7) evaluation of the affected uterine tube, using traction, if necessary, with a Babcock forceps and gauze, 8) salpingectomy or salpingostomy, 9) washing of the pelvic cavity using saline solution, and 10) closure of the cavity using absorbable threads in a single layer.

Compiled information: maternal age, gestational age, serum $\beta$-hCG level, mass size on ultrasound, identification of fetal cardiac activity, type of procedure (salpingectomy or salpingostomy), and total surgical time.

Twelve cases of ectopic pregnancy treated through posterior colpotomy were identified. Their maternal age varied from 20 to 41 years (mean, 30.3 years; standard deviation [SD], 6.8). Salpingectomy was performed in 10 cases and salpingostomy in 1 case. In the remaining case, it was discovered during surgery that the woman had tubal abortion; a slightly dilated tube was the sole finding. Consequently, only peritoneal lavage was performed. Laterality was equally distributed in the sample, and the volume of blood found in the peritoneal cavity ranged from 0 to $200 \mathrm{~mL}$ (mean, $80 \mathrm{~mL}$ ). The surgical time ranged from 30 to 70 minutes (mean, 42.5 minutes; SD, 11.2), accounted from the anesthesia start time to the operating room exit. According to the service protocol for vaginal procedures, food intake was allowed 6 hours after the surgery, and 8 patients were discharged within 12 hours of the procedure. At discharge, the women were asked regarding the post-operative pain levels and degree of satisfaction with the procedure. None of the women complained of pain, and all reported a high degree of satisfaction.

Seven days after discharge, the patients returned to the hospital for evaluation of persistent symptoms or complications. Histopathological results were communicated 40 days after the procedure, when they were again inquired over general well-being. No complications were reported; there were no cases of post-operative infection, and all women reported no persistent symptoms at 7 and 40 days. The only patient who underwent salpingostomy also received hysterosalpingography 6 months after the procedure, which showed patent uterine tubes.

The compiled data for the ectopic pregnancies treated through posterior colpotomy in the study are shown in Table 1.

\section{Discussion}

Surgical treatment of ectopic pregnancy has been routinely performed through laparotomy until Shapiro and Adler de- 


\section{Obstetrics \& Gynecology Science}

Tábata Longo da Silva Machado, et al. Ectopic pregnancy treatment

Table 1. Characteristics of the cases of ectopic pregnancies treated through posterior colpotomy $(n=12)$

\begin{tabular}{|c|c|}
\hline Characteristics & Value \\
\hline \multicolumn{2}{|l|}{ Gestational age (wk) } \\
\hline Mean & 7.7 \\
\hline Range & $6.0-11.8$ \\
\hline \multicolumn{2}{|l|}{ Serum $\beta$-hCG levels } \\
\hline Mean (mIU/mL) & $7,786 \pm 5,016$ \\
\hline Range (mlU/mL) & $1,012-15,511$ \\
\hline$>5,000^{\mathrm{a})}$ & $9(75)$ \\
\hline \multicolumn{2}{|c|}{ Largest mass diameter on ultrasound } \\
\hline Range (mm) & $11-69$ \\
\hline$\geq 35 \mathrm{~mm}$ & $6(50)$ \\
\hline \multicolumn{2}{|l|}{ Fetal cardiac activity } \\
\hline Present ${ }^{a)}$ & $6(50)$ \\
\hline Absent & $6(50)$ \\
\hline \multicolumn{2}{|l|}{ Procedure performed } \\
\hline Salpingectomy & $10(83.3)$ \\
\hline Salpingostomy & $1(8.3)$ \\
\hline Peritoneal lavage only & $1(8.3)$ \\
\hline \multicolumn{2}{|c|}{$\begin{array}{l}\text { Values given are the mean } \pm \text { standard deviation or number (\%). } \\
\text { hCG, human chorionic gonadotropin. } \\
\text { a) Risk factors for a poor prognosis in response to treatment with } \\
\text { methotrexate [2]. }\end{array}$} \\
\hline
\end{tabular}

scribed the laparoscopic approach in the early 1970s [5]. After previous studies have reported advantages regarding blood loss, painkiller use, hospitalization time, and inpatient costs - with a similar reproductive prognosis - laparoscopy was established as the gold standard method for women who are clinically stable. Unfortunately, laparoscopy is not available in the emergency departments of most public Brazilian hospitals, indicating that all patients who are not eligible for expectant or pharmacological treatment ultimately undergo laparotomy.

A few years ago, Pinto et al. [6] described the successful treatment of 18 cases of ruptured ectopic pregnancy through posterior colpotomy in a public Brazilian hospital. They emphasized the good results obtained along with short hospitalization times and the viability of the approach in hospitals that are equipped with the basic material required for vaginal surgery. In the present study, similar results were reported, and we found additional information related to gestational age, serum $\beta$-hCG level, mass size on ultrasound, and fetal cardiac activity at the time of surgery. The procedure was feasible in the setting of a broad variety of these factors. In a preliminary report, we also observed that the procedure can be performed by residents with only modest experience with vaginal surgery, under the guidance of an experienced surgeon [7].

Farrell and Al-Ghasham [8] from Canada have reported their positive experience with 2 cases of tubal pregnancy treated with posterior colpotomy. The first patient refused to undergo laparoscopy as she did not wish to have incision scars in her abdomen, and approach through colpotomy allowed treatment to be successful while respecting her wishes. The second patient had an early ectopic pregnancy with a diameter of $2 \mathrm{~cm}$ on ultrasound and low serum $\beta$-hCG levels; however, pharmacological treatment was not offered because of concerns on the patient's ability to comply with the protocol [8]. We want to draw attention to 2 aspects from this report. First, there was a challenge concerning the management of women with early ectopic pregnancies who are unable to comply with the protocol for methotrexate use. In our scenario, that is a frequent situation, and we consider laparotomy to have a disproportionate disadvantage, especially in obese women or in those who have previously undergone abdominoplasty. Second, even when laparoscopy was available, the vaginal approach was offered as an option. This may seem inappropriate considering that laparoscopy is currently the gold standard for the treatment of ectopic pregnancies. However, it is important to consider that even though superiority of laparoscopy over laparotomy has been shown, there have been no studies comparing laparoscopy with vaginal surgery in the management of ectopic pregnancies.

We could not find other studies on the vaginal route for tubal ectopic pregnancy treatment published after the introduction of laparoscopy. Earlier publications, mostly from the 1950s and 1960s, showed that the vaginal route was appropriate for the diagnosis and treatment of ectopic pregnancies. However, the clinical settings contemplated in those studies cannot be compared to those currently observed, as serum $\beta$-hCG dosing or ultrasound was not available at the time; this indicates that ectopic pregnancy usually presented late and with symptoms [4,9-13]. As diagnosis is made much earlier at present, we speculate that patient outcomes are even better than those described 50 years ago.

In conclusion, we present a series of 12 cases in which posterior colpotomy has been found to be a feasible approach 


\section{Obstetrics \& Gynecology Science}

Vol. 62, No. 6, 2019

for the treatment of ectopic pregnancy. Further studies with a larger number of patients may be needed to strengthen these findings and to establish a comparison among posterior colpotomy, laparoscopy, and laparotomy in the treatment of ectopic pregnancy.

\section{Conflict of interest}

No potential conflict of interest relevant to this article was reported.

\section{Patient consent}

Informed consent was waived because of the retrospective study design.

\section{References}

1. Creanga AA, Syverson C, Seed K, Callaghan WM. Pregnancy-related mortality in the United States, 20112013. Obstet Gynecol 2017;130:366-73.

2. Elito Junior J, Montenegro NA, Soares Rda C, Camano L. Unruptured ectopic pregnancy: diagnosis and treatment. State of art. Rev Bras Ginecol Obstet 2008;30:149-59.

3. Panelli DM, Phillips CH, Brady PC. Incidence, diagnosis and management of tubal and nontubal ectopic pregnancies: a review. Fertil Res Pract 2015;1:15.
4. Kelly H. Treatment of ectopic pregnancy by vaginal puncture. Bull Johns Hopkins Hosp 1896;7:209.

5. Shapiro HI, Adler DH. Excision of an ectopic pregnancy through the laparoscope. Am J Obstet Gynecol 1973;117:290-1.

6. Pinto HC, Jung LK, Wendland E, Heineck SC. Treating ectopic pregnancy with colpotomy. Rev Bras Ginecol Obstet 2012;34:118-21.

7. Zanatta A, Maia T, Zingler E, Reis PR, Alfredo Filho CA, Zaconeta AC. Treatment of first trimester tubal ectopic pregnancy through posterior colpotomy: residents can easily do it. J Minim Invasive Gynecol 2015;22:S250.

8. Farrell SA, Al-Ghasham H. Management of ectopic pregnancy through a posterior colpotomy: two cases. J Obstet Gynaecol Can 2008;30:1137-9.

9. Draa CC, Baum HC. Posterior colpotomy: an aid in the diagnosis and treatment of ectopic pregnancy. Am J Obstet Gynecol 1951;61:300-11.

10. Daly MJ. Posterior colpotomy for the diagnosis and treatment of pelvic disease. Am J Obstet Gynecol 1957;74:623-8

11. Wooten EL. Use of posterior colpotomy in the diagnosis and treatment of ectopic pregnancy and other lesions of the pelvis. Am J Obstet Gynecol 1960;80:727-33.

12. Cherny WB, Wilbanks G, Peete CH Jr. The management of ectopic pregnancy by colpotomy. South Med J 1962;55:568-72.

13. Culton YG, Van Ostrand JR. Colpotomy as a definitive operation in ectopic pregnancy. Obstet Gynecol 1967:29:279-83. 